\title{
Mediación pedagógica en la narrativa visual de cursos virtuales introductorios a licenciaturas
}

\author{
Sandra Acevedo-Zapata ${ }^{2}$ \\ Diana Marcela Pinto-Parra ${ }^{3}$ \\ Astrid Yandira Lemos-Rozo ${ }^{4}$
}

Recibido: 04-05-2019

Aceptado: 04-09-2019

\section{Resumen}

Este artículo es producto del proyecto de investigación Subjetividad, tecnología y educación a través de la mediación pedagógica de la narrativa visual en cursos virtuales (PIE 002 de 2016 ECEDU-UNAD). Luego de aplicar una metodología de investigación documental, se presentan las nociones encontradas sobre las dimensiones de la mediación pedagógica en el contexto de la comunicación de la cultura visual en los procesos educativos virtuales, y la reflexión sobre la construcción de subjetividades en estas interacciones. Es así como el artículo se organiza en tres secciones a modo de nodos conceptuales: el primero es la mediación pedagógica en los entornos virtuales de aprendizaje; el segundo es la evaluación de la mediación pedagógica, y el tercero aborda subjetividad y

1. Artículo producto del proyecto de investigación PIE 002 de 2016 ECEDU de la UNAD. Subjetividad, tecnología y educación a través de la mediación pedagógica de la narrativa visual en cursos virtuales.

2. Licenciada en Psicología y Pedagogía; magíster en Educación; doctora en Ciencias Gerenciales. Docente de planta de la UNAD.

Correo electrónico: sandra.acevedo@unad.edu.co, sandrasaz359@gmail.com ORCID: https://orcid.org/0000-0003-0518-0234

3. Licenciada en Filosofía; magíster en Desarrollo Educativo y Social. Docente de la UNAD.

Correo electrónico: diana.pinto@unad.edu.co

ORCID: https://orcid.org/0000-0002-7283-8764

4. Licenciada en Educación Básica con Énfasis en Humanidades e Inglés; magíster en Educación.

Correo electrónico: astrid.lemos@unad.edu.co

ORCID: https://orcid.org/0000-0002-7611-0922 
tecnología: la expresión en la narrativa visual. Luego, a modo de contrastación, se presenta lo encontrado en la observación de los cursos y las respuestas de los estudiantes frente a la propuesta de la narrativa visual de los cursos virtuales.

Palabras clave: educación virtual, evaluación, imagen, jóvenes, mediación pedagógica, narrativa visual, subjetividad, tecnología.

\title{
Pedagogical mediation in the visual narrative of bachelor's degrees introductory virtual courses
}

\begin{abstract}
This article is the product of the research project Subjectivity, technology and education through the pedagogical mediation of visual narrative in virtual courses (PIE 002 of 2016 ECEDU -UNAD). Based on a documentary research methodology, the article presents findings regarding pedagogical mediation in the context of communication of visual culture in virtual educational processes and reflects on the construction of subjectivities in these interactions. The article is organized in three conceptual sections: the first looks at pedagogical mediation in virtual learning environments; the second evaluates pedagogical mediation, and the third addresses subjectivity and technology: expression in the visual narrative. The article then presents findings from the observation of the courses and the students' responses to the visual narrative proposal for the virtual courses.
\end{abstract}

Keywords: virtual education, evaluation, image, youth, pedagogical mediation, visual narrative, subjectivity, technology. 


\section{Introducción}

El proyecto PIE 002 del 2016, de la Escuela de Ciencias de la Educación de la Universidad Nacional Abierta y a Distancia (ECEDUUNAD), indagó por las dinámicas de los cursos virtuales introductorios pertenecientes a las licenciaturas de dicha Escuela, desde la siguiente pregunta: ¿cómo se presenta la mediación pedagógica y se caracterizan las dimensiones, criterios e indicadores de la narrativa visual en dichos cursos? Para tal efecto, se realizó un proceso de investigación documental que sirvió de referente para identificar y construir dimensiones y criterios, que permiten comprender las transformaciones en la comunicación a través de las imágenes con las narrativas visuales en las propuestas pedagógicas de los cursos virtuales, que fue el fundamento para un estudio focal con estudiantes de los cursos y aportó los insumos para la construcción de un instrumento de encuesta.

Para el trabajo documental que redundó en el presente artículo, se realizaron las actividades de rastreo documental, sistematización de la información en matrices de doble entrada, en las que se identificaron y definieron las dimensiones que permitieron describir la mediación pedagógica en la narrativa visual en los cursos virtuales de la ECEDU en el nivel introductorio de las licenciaturas que forman profesores para diferentes áreas del conocimiento y en diferentes niveles de educación.

\section{Metodología}

Se realizó una investigación descriptiva que buscó indagar las dimensiones y criterios para evaluar la mediación pedagógica de las narrativas visuales en las propuestas pedagógicas de los cursos virtuales introductorios, de las licenciaturas de la ECEDU de la UNAD. En la primera etapa, se realizó un proceso de revisión documental, para lo cual se retomó la metodología propuesta por Acevedo (2018) y, a partir de allí, se retomaron artículos de revis- 
tas de educación y ciencias sociales que abordaran alguna de las variables y dimensiones del estudio, tomando como referencia el periodo comprendido entre el 2009 y el primer número del 2018. Fueron revisados un total de 87 artículos pertinentes para este balance, cuyos criterios de selección fueron las variables mediación pedagógica, narrativa visual, subjetividad, y educación y tecnología, identificando las dimensiones que las configuran.

Los nodos en los que se organizan los resultados surgieron del proceso de clasificación y sistematización de los artículos que cumplían con los criterios de selección. Es importante resaltar que los artículos analizados tienen como autores investigadores del campo de la educación y de la comunicación, que han aportado al campo de la reflexión sobre la imagen y las posibilidades que brindan las tecnologías de la comunicación.

Siguiendo a Acevedo (2018), el resultado de la recolección y clasificación de la información se sistematizó en matrices de doble entrada, en las que se ubicaron las dimensiones centrales, organizándolas en relaciones funcionales con las nociones vinculadas. La estructura del artículo inicia con una pequeña reflexión sobre el contexto contemporáneo de los entornos virtuales, en los que se han dado cambios que afectan la relación pedagógica. Luego, se presentan los hallazgos con los nodos conceptuales correspondientes a las dimensiones y los indicadores que las configuran. Finalmente, se cierra con lo encontrado en la observación de los cursos y la percepción de los estudiantes.

\section{El contexto de los entornos virtuales de aprendizaje}

El avance de la tecnología ha posibilitado la construcción de entornos virtuales de aprendizaje y ha transformado la educación en un campo de posibilidades infinitas, por los cambios en la percepción y el uso del espacio y el tiempo en estos escenarios. Esto no se debe a que los procesos educativos se limitan a encuentros 
presenciales entre sujetos, sino que permiten una conexión desde cualquier lugar del mundo y una comunicación que trasciende hacia nuevas formas de existencia y de relación, transformando las subjetividades de todos los actores educativos con un cambio radical de la cultura escolar, las prácticas pedagógicas y las estrategias didácticas.

Las ventajas que ha proporcionado este panorama y que se hacen cada vez más tangibles son la rapidez con la que progresan las comunicaciones en todos los ámbitos, las posibilidades que se crean para los avances en la ciencia y el bienestar de los seres humanos. Según Langer (2016), se dan posibilidades para los jóvenes con la emergencia de productores de todo tipo de material multimedia, tales como imágenes, videos, blogs, entre otros, lo que nos ha permitido no ser solo espectadores sino creadores. Los jóvenes entre 15 y 29 años son considerados como la generación que ha dejado atrás las formas de comunicación tradicionales, para dar paso a formas más rápidas de interactuar.

De ahí que cerca de un tercio de los menores de 24 años jamás haya tocado un periódico en papel, o que la televisión haya sido desbancada por la web como fuente de noticias principal...para esta generación de Nativos Digitales, comunicarse de forma sencilla, barata e inmediata, es algo tan natural como lo pudo ser para generaciones anteriores disponer de telefonía fija en los domicilios. (Martín Barbero, 2012, p. 16)

Los ambientes virtuales de aprendizaje privilegian este lenguaje visual en sus narrativas; sin embargo, no siempre es explícita la mediación pedagógica que lleva la incursión de estas formas de comunicación y que privilegian el aprendizaje. Los procesos de subjetividades de los actores educativos se han visto modificados en estas configuraciones mediáticas; Barrantes, Padilla y Riaño (2016) plantean que es necesario propiciar una reflexión crítica en torno al lenguaje visual que prevalece en la educación virtual y su intencionalidad pedagógica. 
Se pretende describir las dimensiones y criterios que permitan una evaluación de las categorías expuestas, a partir de los estudios previos en el área, una mayor comprensión de las narrativas visuales y su repercusión en las subjetividades, así como evidenciar la mediación pedagógica inmersa o ausente en los ambientes virtuales educativos.

\section{Mediación pedagógica en los entornos virtuales de aprendizaje}

La virtualidad se define como "una simulación mediada de la realidad que se manifiesta de manera sistemática y evaluando el proceso de aprendizaje y enseñanza bajo objetivos específicos, empleando una combinación de recursos humanos y materiales para conseguir un aprendizaje más efectivo" (Martínez, Quimbayo, \& Bustamante, 2010, p. 25). Esta virtualidad se integra a la educación con la finalidad de incluir los avances tecnológicos y sus características de rapidez y efectividad en los procesos de aprendizaje, y para expandir sus posibilidades de tiempo y espacio. En este proceso se modifican también los lenguajes tradicionales de las estrategias pedagógicas y se privilegian las formas de comunicación más ágiles y sucintas.

Los sujetos protagonistas de estas prácticas configuran sus subjetividades de un modo que difiere de la cultura escolar tradicional; de acuerdo con Gutiérrez-Castro (2015), la subjetividad del joven se constituye desde los procesos histórico, social y cultural, encarnados en los cuerpos desde la comprensión de experiencias diversas e interactivas. Las tecnologías actuales median las identidades de los jóvenes de formas diversas, poco predecibles y a grandes velocidades. Estamos involucrando redes, interconexiones e intercambios, cuando hablamos de identidad en la sociedad de la información, según la definición dada por Barbero (2012):

Significa en términos mundiales, la puesta en marcha de un proceso de interconexión mundial, que conecta todo 
lo que informacionalmente vale- empresas e instituciones, pueblos e individuos-, al mismo tiempo que desconecta todo lo que no vale. (p. 12)

En estas formas de comunicación, el aprendizaje no es más una transmisión de conocimientos, sino una apropiación de las experiencias, que se han trasladado cada vez más de espacios físicos tradicionales a los ambientes virtuales. Según Gutiérrez-Castro (2015), las subjetividades de los jóvenes se exteriorizan en el lenguaje visual, "un lenguaje que, más allá de mostrar formas de acción, hace posibles procesos de comunicación donde los seres humanos modifican su visión de la realidad y se manifiestan socialmente, cuando, mediante una imagen, dan a conocer su ideología y subjetividad" (p. 100); es allí donde se manifiesta la cultura juvenil, influenciada por los elementos de la sociedad de la información. Complementando esta visión, Arriaga y Aguirre (2012, citado por Álvarez, 2012) argumentan lo siguiente:

Desde un punto de vista educativo, lo que me interesa del arte o la cultura visual, concebidos como experiencia, es su capacidad para convertirse en detonante de la transformación personal de sus usuarios, tanto en su calidad de productores como de receptores. (p. 210)

En este sentido, Martínez et al. (2010) describen algunas características de los entornos virtuales de aprendizaje, refiriendo las interacciones que se presentan en estos ambientes:

Las interacciones entre tutores y estudiantes, las cuales son de dos tipos: asincrónica y sincrónica; deben ser soportadas por plataformas robustas y ambientes virtuales de aprendizaje diseñadas por sistemas educativos que tienen un modo de proceder bajo una intencionalidad pedagógica conciliada con la comunidad académica. ( $p$. 74)

La comunicación que se propicia en la virtualidad requiere de unas estrategias pedagógicas y didácticas, que privilegien la re- 
flexión crítica en torno a las imágenes y narrativas visuales, que capturan la atención de los estudiantes, pero no siempre logran una armonía entre la cultura escolar y la cultura de los jóvenes.

A partir del rastreo realizado, se hizo más evidente una problemática manifestada por los jóvenes inmersos en sistemas educativos tradicionales, quienes generalmente son creadores de sus propias narrativas visuales y en las que plasman sus identidades. Debido a los avances tecnológicos y a las herramientas digitales, pueden difundir en redes sus producciones e intercambiar subjetividades; a pesar de ello, la Escuela y, por ende, sus currículos educativos, continúan incrédulos del potencial que contienen las imágenes y el material visual, como lo argumentan Arriaga, MarceIlán, Calvelhe, Aguirre y Olai (2012):

Podemos decir, por tanto, que los saberes que manejan para la producción visual y los saberes escolares se encuentran bastante alejados entre sí. Solamente se reconoce cierto "aprovechamiento" de los saberes escolares para su actividad productora cuando se trata del aprendizaje de técnicas. (p. 199)

Los estudiantes no consideran relevante el conocimiento que se aborda en la escuela para sus creaciones, ni lo relacionan con las narrativas visuales que se integran en las estrategias didácticas.

En los ambientes virtuales de aprendizaje, vemos que la comunicación se ajusta un poco más a las exigencias de la sociedad de la información, con una alta inclusión de lenguaje audiovisual. Sin embargo, los procesos de lectura y escritura siguen teniendo una mayor importancia con respecto a las imágenes para los docentes, aún en la virtualidad. De acuerdo con Álvarez (2012), es necesario que los docentes conozcamos a profundidad los elementos y la intencionalidad que forman parte de este lenguaje, así como su potencial pedagógico y el impacto que pueda tener en un aprendizaje más efectivo. De esta forma, también como creadores de este lenguaje podremos incluir elementos que permitan explicitar una intencionalidad clara de proporcionar escenarios y experiencias de 
aprendizaje. Gómez y Moreno (2012) abordan las narrativas visuales, desde el concepto de "pensamiento visual" y desde la reflexión en torno a las creencias de los docentes e instituciones educativas acerca de la falta de procesos intelectuales formales en el lenguaje visual:

Se han desarrollado estudios que pretenden demostrar que las imágenes visuales no están confinadas a la esfera de lo meramente perceptual, pues su interpretación implica el despliegue de capacidades para la abstracción y la formalización [...]. Así pues, la imagen visual mezcla expresión, reflexión y conocimiento. (Gómez \& Moreno, 2012, p. 126)

El reto para mejorar la relación pedagógica y generar mediaciones pedagógicas pertinentes consiste en propiciar experiencias de aprendizaje que sean consecuentes con la cultura que viven los estudiantes fuera de las instituciones educativas. En este contexto, el lenguaje visual, y en especial la imagen, son esenciales en la comunicación efectiva en los ambientes virtuales de aprendizaje. Se hace necesario hacer explícitas las intencionalidades pedagógicas que traen consigo los procesos educativos y los actores que estamos involucrados como creadores y consumidores de dicho lenguaje, privilegiando la reflexión crítica y un aprendizaje profundo.

\section{Evaluación de la mediación pedagógica en la educación virtual}

A partir de las transformaciones dadas recientemente en la concepción de la evaluación dentro de los procesos educativos, pasando de ser considerada medición cuantitativa obtenida a partir de la revisión de un producto o tarea, a la posibilidad de potenciar las fortalezas y mejorar las debilidades en el aprendizaje de los estudiantes, se hace necesario innovar en las formas como se realizan las evaluaciones, para que estas cumplan realmente una función formativa. Asimismo, estas nuevas formas de ver la evaluación han 
ampliado su papel en el universo educativo, pasando a ser motivo de reflexión permanente sus posibilidades, alcances y aplicaciones. Rodríguez, Ibarra, Gallego, Gómez y Quesada (2012) plantean lo siguiente:

Mediante la educación en la evaluación se puede aprender a establecer criterios (y con ellos prioridades), a reflexionar sobre lo positivo y lo negativo de las realidades, a valorar (y comparar) los objetos de evaluación y sobre todo, a tomar decisiones fundamentadas y justificadas. De esta forma se puede favorecer que el estudiante autorregule su aprendizaje y fomentar su aprendizaje autónomo $y$, desde una perspectiva profesional, que se adapte más fácilmente a los cambios y esté capacitado para asumir responsabilidades. (p. 3)

Desde esta perspectiva, la evaluación ocupa un puesto clave y se integra en todos los momentos del proceso formativo. De allí que sea el docente quien permanentemente debe evaluar si sus propuestas educativas están bien diseñadas y permiten alcanzar los objetivos de formación esperados. En ese orden de ideas, y retomando a González, Verdugo y Mortingo (2017) y Ramírez y Beltrán (2017), la evaluación no está dirigida solo al estudiante y la medición de sus logros académicos, sino que integra la totalidad de los elementos participantes en los procesos de aprendizaje e involucra a todos los actores que intervienen en la educación.

Pérez (2016) llama la atención sobre la necesidad de la calidad en la evaluación, y afirma lo siguiente:

La calidad de la evaluación está relacionada con criterios como la coherencia entre sus planteamientos y tales objetos y objetivos, la suficiencia de esta para constatar logros y carencias, la adecuación a los mismos ante la gran diversidad de aquellos $y$, desde luego, el correcto uso de la información recogida, puesta al servicio de la mejora de la realidad objeto de evaluación y de cuantas personas tengan relación con esa realidad (partes interesadas y 
afectadas, concepto, a mi juicio, más adecuado que el de "audiencias"). (p. 16)

En estas nuevas concepciones acerca de la evaluación como elemento integral e integrador del proceso educativo, se entiende que las mediaciones pedagógicas deben ser objeto de evaluación para revisar su pertinencia respecto al logro de los objetivos educativos propuestos. Ahora bien, constituyendo la narrativa visual, y más concretamente la imagen, un elemento educativo relevante en la actualidad, siendo ampliamente utilizados tanto en educación presencial como virtual, surgen inquietudes sobre qué elemento es importante tener en cuenta a la hora de proponerlas en las actividades educativas.

La evaluación puede ser abordada desde parámetros que, en el marco de referencia de la evaluación orientada al aprendizaje (Carless, Joughin, \& Liu, 2006), establecen tres requisitos básicos para que la evaluación se enfoque en desarrollar aprendizajes valiosos a lo largo de toda la vida. Dichos requisitos son:

- Las tareas de evaluación deben ser tareas de aprendizaje.

- La retroalimentación debe convertirse en retroalimentación generalizable o proalimentación (feedforward).

- La evaluación debe implicar activamente a los estudiantes.

También se asume la evaluación de la mediación pedagógica desde ámbitos, como lo plantea Daniel Prieto (citado por Álvarez, 2004), que contempla tres momentos de la evaluación:

- Inicial: para detectar las principales características del objeto a la situación a evaluar. 
- Formativa: realizada durante el proceso para rectificar o confirmar el rumbo y seguir retroalimentando el proceso.

- Sumativa: para medir los logros del proceso desarrollado.

En el mismo sentido, en todos los casos y tipologías de la evaluación se requieren criterios, que se entienden como el nivel de logro de los objetivos específicos. Estos guían al docente en la formulación de estrategias para recopilar información cualitativa y cuantitativa (Avendaño-Castro \& Parada-Trujillo, 2012).

Para el caso específico de la mediación pedagógica, se evidencian las metodologías mediante las cuales la evaluación en educación se asume como un proceso en el que se puede aprender a establecer criterios (y con ellos prioridades); a reflexionar sobre lo positivo y lo negativo de las realidades; a valorar (y comparar) los objetos de evaluación y, sobre todo, a tomar decisiones fundamentadas y justificadas. De esta forma, se puede favorecer que el estudiante autorregule su aprendizaje y fomentar su aprendizaje autónomo, desde una perspectiva profesional, para que se adapte más fácilmente a los cambios y esté capacitado para asumir responsabilidades (Rodríguez et al. 2012).

Otro elemento de la dimensión de evaluación de la mediación pedagógica corresponde a los actores: el estudiante es el principal protagonista de su proceso de aprendizaje, es prosumidor, es decir, un usuario con capacidad de creación de contenido de narrativas abiertas en diferentes formatos hipermediales, con capacidad de consumirlas y compartirlas con el mundo. Por otra parte, también es usuario con capacidad de elección y de participación en incesante expansión e integrado a estructuras de las redes que parecen no tener ni principios ni fin. El docente es un guía del aprendizaje del estudiante y verifica, según Rodríguez y Mandagarán (2014):

La consolidación de competencias híbridas (e-skills) propias de los entornos postdigitales, que estimulan e in- 
ducen creatividad e innovación, aprendizaje basado en proyectos, experimentación en franca actitud exploratoria y de aprendizaje permanente (para probar, desarmar, ver que hay dentro del proceso y del objeto, prototipar, reflexionar y realimentar el proceso al volver a intentar). Asimismo, contacto a distancia, integración a redes sociales, trabajo en equipo, fluidez en la comunicación, interacción colaborativa (para conectarse, complacerse, escuchar, establecer vínculos y encontrar otras ideas y estímulos esencialmente diferentes). Finalmente, en pos de la construcción significativa del conocimiento, resultan reveladoras aquellas competencias que favorecen la auto-gestión. (p. 198)

Por lo tanto, la evaluación de la mediación pedagógica de la narrativa visual en los cursos virtuales implica la observación de las estrategias propuestas por los profesores y los recursos dispuestos, así como la relación que se establece y los criterios que se utilizan, y requiere fundamentalmente valorar la percepción de los estudiantes de la experiencia vivida en el desarrollo de los cursos.

\section{Tecnología y subjetividad la expresión en la narrativa visual}

Al abordar la mediación pedagógica de la narrativa visual, fue necesario reconocer que en los entornos virtuales se reconfigura la educación en el escenario de las tecnologías. Se asume la educación, como lo plantea Acevedo (2018), como acción comunicativa que circula en la relación pedagógica, como proceso intersubjetivo y que a la vez propicia procesos intrasubjetivos en la interacción social experiementada en entornos tecnológicos de mediación cultural.

En la relación entre educación y tecnología, el escenario es la subjetividad, y se abordan dimensiones como lo político del sujeto que, según Sáenz (2010), es la esfera propia de lo humano y de su 
relación con la sociedad, ya que en los entornos tecnológicos se pone en evidencia los elementos que configuran las identidades y la subjetividad; por esta razón, se requieren reglas de juego o metodologías que propicien relaciones de poder enmarcadas en la democratización desde la justicia y es necesario tener en cuenta lo sugerido por Pérez, Laverde y Murcia (2016), al señalar que la formación política es fundamental y se configura a lo lardo del proceso educativo de los sujetos en todos los contextos de su socialización.

Es necesario tener presentes los riesgos que se dan en la educación virtual, principalmente el relacionado con la posible instrumentalización por el desplazamiento del lugar del maestro, si se llega a volver un simple calificador y pierde su lugar en la interacción con los estudiantes. Como lo plantea Acevedo (2008), la relación intrasubjetiva entre los actores del proceso educativo se materializa en la formación política a través de las prácticas comunicativas y pedagógicas, y estas son necesarias porque le brindan al sujeto los elementos para configurar su estructura simbólica y cultural que le permitirá tener las bases para un pensamiento crítico.

Para abordar lo subjetivo en la mediación pedagógica, es necesario abordar la narrativa visual, que se concibe como las historias singulares y concisas con función de recurso didáctico, que implican recursos originales como la imagen. Estas narraciones privilegian el aprendizaje colectivo, y una expresión del lenguaje visual en una sociedad interconectada (Rodríguez \& Mandagarán, 2014).

Sánchez (2009) plantea algunos procedimientos para el manejo de la imagen, entre los cuales llama la atención la "ampliación de la imagen", lo que refiere a ver más allá de lo que la imagen muestra en sí misma. Existen cuatro formas de ver la imagen:

a) Espacialmente: "observamos la imagen imaginando lo que hay alrededor de ella" (p. 4). 
b) Temporalmente: "suponemos qué ha pasado antes del momento que capta la imagen o qué pasará después" (p. 5).

c) Socialmente: "deducimos los aspectos sociales de la imagen tales como clase social, relaciones personales, ambiente en el que viven, etc." (p. 5).

d) Comunicativamente: "formulamos hipótesis sobre lo que están hablando las personas que aparecen en la imagen, cómo se sienten, qué intentan expresar mediante su mirada, postura, gestos, etc. ¿De qué están hablando? ¿Están felices o tristes?" (p. 5).

Por su parte, Barragán y Gómez (2012) proponen la caricatura como recurso educativo que permite la integración de diversas áreas del conocimiento, al estar estructurada multidimensionalmente de la siguiente manera:

Es un medio de representación (dimensión simbólica), es una forma de conocimiento (dimensión psicológica), se refiere a una época en particular (dimensión sociocultural) y asume posiciones evaluativas de la realidad (dimensión axiológica). Un aprovechamiento de la imagen que no pierda de vista tales dimensiones contribuirá, sin duda, a lo que se ha denominado formación integral y desarrollo de actitudes críticas. (p. 91)

Continuando con la propuesta del cómic como recurso educativo, Segovia (2009) se centra especialmente en el análisis de tres aspectos que confluyen en la elaboración de una viñeta:

a) La organización del escenario, pues en él podemos observar la capacidad que demuestra el autor para trasladar a un espacio de dos dimensiones, como es el de la viñeta, la tridimensionalidad. 
b) La disposición de los personajes y los objetos en el espacio representado. Esta operación se asemeja a una puesta en escena de los personajes que intervienen en la acción, así como de la forma y organización de los objetos.

c) La función del encuadre en la composición de la viñeta, lo que conlleva tener en consideración el marco que la delimita, comportándose éste como segmento para enfatizar el punto de vista que desea imponer el autor. (p. 7)

Dado lo anterior, se observa la importancia de revisar las imágenes y analizar su pertinencia educativa a la hora de proponer actividades a los estudiantes, para que realmente puedan alcanzarse los objetivos formativos esperados, desde unas intencionalidades claras y concretas, propiciando el desarrollo de capacidades cognitivas y metacognitivas. Por ello, es necesario contar con propuestas de mediación pedagógica de la narrativa visual desde una perspectiva crítica, para integrar las imágenes teniendo en cuenta algunas dimensiones como el contexto espacio-temporal, el contexto sociocultural y el contexto comunicativo.

\section{La observación de los cursos introductorios de las licenciaturas}

Con respecto a la observación de los cursos virtuales introductorios de las licenciaturas en la ECEDU, centrando la exploración de la narrativa visual en la mediación pedagógica que se evidencia en las propuestas pedagógicas, se pudo identificar que se presentan pocos contenidos que hacen uso de la narrativa visual. Aunque el escenario de los entornos virtuales utiliza muchas imágenes y las actividades propuestas tienen el potencial del desarrollo de la narrativa visual, si se organizaran con una mediación pedagógica, propiciarían una actitud crítica y propositiva en los estudiantes. Se encuentra una tendencia a utilizar estos recursos solo como herra- 
mientas para la presentación más organizada y sintética del texto escrito, prescindiendo de la potencialidad de la imagen, dejándola en un plano complementario.

Por otra parte, se encontró en el desarrollo de los foros la participación de un estudiante que envía una imagen de un personaje de un programa infantil que no se relaciona con la actividad, para motivar a los compañeros a participar en el curso. Luego se encuentran actividades como una línea de tiempo que no se integra con una perspectiva crítica ni con una narrativa visual desde una actitud crítica y propositiva en los estudiantes. También puede utilizarse este recurso propuesto solo como herramienta para la presentación más organizada y sintética del texto escrito, prescindiendo de la imagen. Se puede establecer que desde las guías de actividades no se propicia el uso de la imagen como recurso de expresión de las ideas, como alternativa al texto escrito.

Hay que apuntar también que los lineamientos institucionales restringen el modo de usar la imagen en los cursos virtuales. Se evidencia una falta de narrativas visuales y no se han incluido videos e imágenes; resalta en cambio la cantidad abrumadora de lecturas en formato pdf. En algunos casos, se sugiere un mapa mental como actividad, pero no se especifica que se incluyan imágenes, por lo que los resultados podrían ser otro producto de escritura.

Es evidente la necesidad de integrar elementos de la cultura visual en los cursos, y más aun siendo de primera matrícula, ya que esto contribuye a motivar a los estudiantes y a privilegiar su creatividad y sus expresiones artísticas. Se podría observar que en algunos cursos la estética del arte está completamente excluida, y que algunos cursos se conforman casi en su totalidad por un sistema lineal de producción textual.

Por otra parte, existe una propuesta de la licenciatura en etnoeducación, en la que se evidencia un mayor énfasis en el trabajo con vídeos como parte de la propuesta pedagógica, lo que puede obedecer a la necesidad de comunicarse con estudiantes que son oriundos de diferentes culturas y dominan diversas lenguas, en cu- 
yos casos se hace más eficiente el uso de la narrativa visual. También se encuentra que, en ese mismo curso se propicia la reflexión sobre su propia vida y su contexto, que debe materializarse en un video que presentan los estudiantes como fruto de su trabajo. Sin embargo, hace falta centrarse en una propuesta estructurada de mediación pedagógica en la que el video supere la condición de recurso, para construir pensamiento crítico a través de las actividades y estrategias pedagógicas en las que la narrativa visual tenga un énfasis más profundo y potencie los procesos de formación de maestros con el papel político que deben realizar en sus comunidades.

Desde las guías de actividades, la mediación pedagógica implica la apropiación de parámetros que lleven al estudiante al uso de la imagen como recurso de expresión de sus ideas, como una alternativa al texto escrito. Sin embargo, para ello es necesario dar la pauta desde las estrategias, los contenidos y los entornos del aula virtual.

En general, se requiere una mirada que integre la narrativa visual en la mediación pedagógica para potenciar los procesos de reflexión crítica, superando la mirada instrumental a la que quedan reducidos tanto las imágenes como los sujetos que participan en el acto educativo, cuando se construyen relaciones sin la profundidad y las apuestas pedagógicas requeridas para que se integre al proceso de formación de los futuros maestros.

Retomando a Acevedo (2017), se puede inferir que la mediación pedagógica de la narrativa visual requiere ser asumida desde la perspectiva de la innovación curricular como un proceso cultural, en el que se debe hacer énfasis en la subjetividad y sus formas de expresión, para que permitan el reconocimiento de la diversidad con estrategias pedagógicas, de manera que brinde herramientas para superar la exclusión. La mediación pedagógica debe propiciar las relaciones de diferenciación y de creación, como lo sugiere Foucault (2008), y de esta manera las experiencias que propicia la mediación pedagógica pueden permitir la construcción propia con el trabajo biográfico y el análisis crítico y social. 
Vale la pena resaltar que, en contraste con la perspectiva de las investigadoras, fue sorpresivo que en los resultados de la encuesta de percepción aplicada a los estudiantes se encontró, a nivel general, que un alto porcentaje (aproximadamente el 60\%) de las respuestas está totalmente o medianamente de acuerdo con la presencia de las narrativas virtuales en los cursos y sus usos educativo; al hablar de estos elementos como posibilidades de reflexión, una gran mayoría los percibe como elementos más allá de la dimensión decorativa. Desde luego, esto evidencia que los estudiantes en la educación virtual son los protagonistas y con una apropiada mediación pedagógica será posible potenciar aún más la imagen y las narrativas visuales en la inclusión de las guías de aprendizaje y el campus virtual.

\section{Conclusiones}

Es innegable la preeminencia de la narrativa visual y, más concretamente, de la imagen en las dinámicas comunicativas actuales de la población joven. El uso de los dispositivos móviles y el chat han propiciado cambios en las prácticas del lenguaje y nuevas formas de interpretar la realidad, que van más allá de la palabra hablada y escrita. Por ello, la potencialidad del uso de la imagen en el ámbito educativo es tan amplia y requiere ser analizada desde diversos ámbitos, uno de ellos, el de evaluar su pertinencia a la hora de plantearse como recurso educativo en las actividades formativas, pues de una propuesta pertinente puede obtenerse el éxito en los objetivos de aprendizaje esperados.

Se puede afirmar que realizar la evaluación de la narrativa visual es pertinente en el contexto de la educación por mediación virtual, pues con ello es posible revisar las potencialidades que brinda el uso de la imagen como recurso pedagógico y didáctico en los entornos virtuales.

Aún hay cierto grado de resistencia de los estudiantes en la consideración de la imagen como herramienta de comunicación al- 
ternativa a la palabra y como generadora de conocimiento académico. Persiste la noción de la imagen como expresión meramente artística y asociada a la disposición de formas y colores.

Los maestros están llamados a promover la apropiación de la narrativa visual desde las actividades de los cursos virtuales y brindar la guía para potenciar su valor en lo académico. Pero también es necesario presentarla como una alternativa de aprendizaje que permita la utilización de diversos recursos y herramientas de las que dispone la web, sea para la consulta de contenidos basados en la imagen o para su creación.

También es necesario poner en juego la evaluación como elemento esencial en la mediación pedagógica de la narrativa visual, ya que puede dinamizar las interacciones en los cursos virtuales. Se requieren procesos de autoevaluación y coevaluación y, además, una metaevaluación de las estrategias pedagógicas propuestas, los recursos y el empoderamiento de la voz de los estudiantes desde su percepción y formación política.

Se puede concluir, a la luz de los datos, que ya hay un camino avanzado en la inclusión de las narrativas visuales, pero aún se requiere una perspectiva pedagógica, como lo plantean García y Cortez (2017), que oriente hacia el pensamiento crítico y reflexivo; por tanto, la formación de maestros tiene como desafío ahondar en las estrategias que permitan generar mediaciones pedagógicas pertinentes, consecuentes con la cultura y el lenguaje visual, para la reflexión crítica en la sociedad del conocimiento y de la cultura digital.

\section{Referencias bibliográficas}

Acevedo, S. (2008). Sujeto, tecnología y educación. Revista Pedagogía y Saberes, 29, 51-55. doi: http://doi.org/c89x 
Acevedo, S. (2018). Revisión de la educación y la tecnología desde una mirada pedagógica. Revista Pedagogía y Saberes, 48, 97-110. doi: http:// doi.org/c89z

Acevedo, S. (2017). Innovación pedagógica y curricular para la inclusión social en la Educación Superior. Revista Pilquen, 14(2), 50-60. Recuperado de http://revele.uncoma.edu.ar/htdoc/revele/index.php/psico/article/ view/1800/pdf

Álvarez, S. (2012). La producción audiovisual hecha por jóvenes como herramienta para el reconocimiento comunitario y la construcción de ciudadanía. La experiencia del proyecto "Mi mirada, Nuestra mirada" en Salta, Argentina. Edarte, Grupo de investigación (Ed.), Investigar con jóvenes: ¿Qué sabemos de los jóvenes como productores de cultura visual? (pp. 204-211). Pamplona: Pamiela-Edarte (UPNA/NUP). Recuperado de https://academica-e.unavarra.es/bitstream/handle/2454/19798/ ProduccionAudiovisual. pdf? sequence $=1 \&$ isAllowed $=y$

Aparicio, O.Y. (2018). Las TIC como herramientas cognitivas. Revista Interamericana de Investigación, Educación y Pedagogía, RIIEP, 11(1). https://orcid.org/0000-0003-3535-6288

Arriaga, A., Marcellán, I., Calvelhe, L., Aguirre, I., \& Olaiz, I. (2012). ¿Jóvenes productor*s de cultura visual? Reflexiones en torno a los resultados de un cuestionario. Edarte, Grupo de investigación (Ed.), Investigar con jóvenes:¿ Qué sabemos de los jóvenes como productores de cultura visual? (pp. 190-203). Pamplona: Pamiela-Edarte (UPNA/ NUP).

Avendaño-Castro, W. R., \& Parada-Trujillo, A. E. (2012). El mapa cognitivo en los procesos de evaluación del aprendizaje. Investigación \& Desarrollo, 20(2), 334-365.

Barrantes, H. A., Padilla, J. E., \& Riaño, F. A. (2016). Perfil del estudiante de pregrado de la Facultad de Estudios a Distancia de la Universidad Militar Nueva Granada. Revista Interamericana de Investigación, Educación y Pedagogía, 9(2), 179-195. 
Barragán, R. A., \& Gómez, W. (2012). El lenguaje de la imagen y el desarrollo de la actitud crítica en el aula: propuesta didáctica para la lectura de signos visuales. Íkala, 17(1), 81-94. Recuperado de http:// www.redalyc.org/articulo.oa?id=255024135006

Carless, D., Joughin, G., \& Liu, N. F. (2006). How assessment supports learning: Learning-oriented assessment in action. Hong Kong: UniversityPress. doi:10.5790/hongkong/9789622098237.001.0001

de la Calle, C. V., Malaver, M. O., Gallego, J. D. M., Rodríguez, M., Flórez, J. C., Henao, C. E. \& Saldaña, R. (2014). Aportes de los doctorados de educación en ciencia, tecnología y sociedad, desde la sistematización de sus investigaciones doctorales científicas y formativas, 2000-2010. Revista Interamericana de Investigación, Educación y Pedagogía, RIIEP, 7(1). DOI: https://doi.org/10.15332/s1657-107X.2014.0001.04

García, G., \& Cortez A. (2017) Estrategias pedagógicas que favorecen el aprendizaje de niñas y niños de 0 a 6 años de edad en Villavicencio - Colombia. Revista Interamericana de Investigación, Educación y Pedagogía, 10(1), 125-143. doi: https://doi.org/10.15332/s1657$107 X .2146$

Foucault, M. (2008). Tecnologías del yo. Madrid: Ediciones Paidós.

Gómez, R., \& Moreno, W. (2012). Las funciones de la imagen visual en el aula. Revista humanidades, 39(1), 123-132. http://revistas.uis.edu.co/ index.php/revistahumanidades/article/view/2641

González, K., Verdugo, N., \& Mortingo, A. (2017) Incidencia de los entornos virtuales de aprendizaje en la calidad de la educación superior, desde el contexto colombiano. Revista Interamericana de Investigación, Educación y Pedagogía, 10(1), 11-24. doi:10.15332/s1657-107X.2154

Gutiérrez-Castro, F. A. (2015). Jóvenes, cultura escolar y comunicación. Magis, 7(15), 97-116. doi: http://doi.org/c892

Langer, E. (2016). La construcción de confianza para el estudio de prácticas de resistencia en la escolarización de jóvenes en contextos de 
pobreza urbana. Revista Interamericana de Investigación, Educación y Pedagogía, 9(2), 113- 137. doi: http://doi.org/c893

Martín-Barbero, J. (2012). Los desafíos estratégicos de la sociedad de la información. Signo y Pensamiento, 23(44), 9-18.

Martínez, B., Quimbayo, A., \& Bustamante, P. (2010). Educación virtual: sentidos, subjetividades y acción pedagógica en contextos multiculticulturales. Mediaciones, 8(10), 63-80. doi: http://doi.org/c894

Pérez, R. (2016). ¿Quo vadis, evaluación? Reflexiones pedagógicas en torno a un tema tan manido como relevante. Revista de Investigación Educativa, 34(1), 13-30. doi: http://doi.org/c895

Pérez, T. H., Laverde T., \& Murcia, L. (2016) Las políticas públicas de orden nacional y distrital de primera infancia, una mirada desde el enfoque de capacidades. Revista interamericana de Investigación, Educación y Pedagogía, 9(1), 76-86. doi:10.22490/25391887.1927

Ramírez, J., \& Beltrán M. (2017). Formación inicial de profesores de ciencias desde los enfoques CTSA y las concepciones Andinas de Vivir bien y Buen vivir. Revista Interamericana de Investigación, Educación y Pedagogía, 10(1), 217-230. doi:10.15332/s1657-107X.2152

Rodríguez, B. D., \& Mandagarán, M. (2014). Pensamiento de diseño y construcción de narrativas visuales. Caso de prácticas didácticas disruptivas en entornos postdigitales. Blucher Design Proceedings, 1(8), 195-199. doi: http://doi.org/c896

Rodríguez, G., Ibarra, M., Gallego, B., Gómez, M., \& Quesada, V. (2012). La voz del estudiante en la evaluación del aprendizaje: un camino por recorrer en la universidad. RELIEVE, 18(2), art. 2. doi: http://doi.org/ c897

Sáenz, K. (2010). Reconocer lo político como una esfera propia del ser humano en la educación virtual. Revista Pedagogía y Saberes, 32, 45-55. doi: http://doi.org/c898 
Sánchez, G. (2009). El uso de las imágenes en la clase E/LE para el desarrollo de la expresión oral y escrita. Suplementos MarcoELE, 8, 1-17. Recuperado de http://marcoele.com/descargas/china/g.sanchez_ imagenes.pdf

Segovia, B., (2010). Desarrollo de la narrativa visual de los escolares con el cómic. Revista Iberoamericana de Educación, 51(5), 1-11. doi:10.35362/ rie5151819 